\title{
The Function of Vessels from the El-Zuma Repertoire
}

As mentioned in Chapter 2, the function of the El-Zuma pottery should be analysed from both social and religious perspectives, hence we need to examine its function in domestic life and also its symbolic function in the realm of ritual and burial ceremonies. Looking at the function of individual vessel types and their role as grave deposits, the author has analysed the material, taking into consideration three main aspects: pottery as containers for grave goods; pottery as a symbol of funerary customs; and pottery as a tool used in the looting of burials. The vessel capacities cited in this chapter have been estimated using the "Calculation of the capacity of a vessel from its profile" guidelines set out by the Centre de Recherches en Archéologie et Patrimoine (http://capacity.ulb.ac.be/sendimage .php?langue $=e n)$, and based on the assumption that vessels were filled up to a level of $1 \mathrm{~cm}$ below the rim.

\section{1 \\ Vessel Function in the Grave Context}

From a social perspective, the tomb is the last 'house' for the physical body of the deceased, and a symbol of the end of earthly life. If we look at the pottery as a part of domestic life, we can distinguish kitchen ware (vessels for the serving and consumption of food and liquids), storage vessels, transport vessels, and specialized vessels such as qawadis, oil lamps, and stands. The function of the vessels is determined from their shape, technological features, traces on their surfaces (e.g. soot), and by examining their context in the grave and studying analogies in the literature.

Globular pots and bowls (Adams' Class U) corresponding to El-Zuma types IV.1-IV.3, V, VI (Adams 1986, 1 and $2: 35,161-162$, Figs $72: 3,4,5 ; 73: 10,11,13)$. The capacity of bowls of type IV ranges from 0.281 to 0.81 in vessels with a rim diameter of less than $20 \mathrm{~cm}$ and a height of $6.5^{-8} \mathrm{~cm}$. Larger vessels with a rim diameter greater than $20 \mathrm{~cm}$ and a height of more than $8 \mathrm{~cm}$ could hold from 1.21 to 3.7 l. Pots of type $\mathrm{v}$ have a capacity ranging from o.6l to 1.31 , while larger pots, such as $\mathrm{Z} 28 / 7$, could hold about 5 l. Clay was added to the base in order to disperse heat during the cooking process. Mahmoud El-Tayeb has pointed out that these vessels can be compared with modern handmade Sudanese pans used for frying meat, which differ in form but also have an extra layer added to the base (Mahmoud El-Tayeb 2012, 100). In the El-Zuma assemblage, some bowls and pots were used as containers for food offerings. Animal bones were found inside these vessels, probably representing parts of animal carcasses prepared as meat cuts (see Volume I, Chapter 8). A large group of pots was burnished, only a few examples were also slipped inside, suggesting that they could have been used for liquids. Traces of fire and soot are visible on the bases of many vessels, which implies that they had been used. However, some examples seem to have served only as grave goods given that they were made from very fragile clay with a large number of seeds used as temper. Such vessels fall apart when handled and probably could not have been in use before their deposition in a grave.

Bowls (Adams' Class C) corresponding to El-Zuma vessels of types II.1-II.3 (Adams 1986, 1 and 2:116, Fig. 26:11, 14; 117, Fig. 27:26; 121, Fig. 29:42-43) and also bowls of type II.4. The capacity of these bowls ranges from 0.31 to 1.5l, with larger vessels holding up to 2.2 . However, the most common capacity in these types is $0.35^{-0.61}$. Most of these bowls, like the goblets and cups presented below, have slipped surfaces, enabling them to hold liquids. Bowls placed in tumuli were probably used as containers for food offerings, as in some tumuli (e.g. T.12, T.13, T.26) they were found to contain animal bones (see Volume I, Chapter 8).

Cups and goblets used for serving food and beverages (Adams' Classes A and B) (Adams 1986, 1 and 2:35, 109 Fig. 19: 9-11, 18; 113 Fig. 23) corresponding to El-Zuma cups of group I, and El-Zuma goblets of group IX. The capacity of cups of types I.1-I.4 ranges from 0.15l to as much as $0.6 \mathrm{l}$, but the average (most common) capacity is $0.3^{-0.45}$ l. Type I.5 cups, which are of more globular shape, have a capacity of $0.6-0.7$ l. Goblets (Ix) have a similar capacity to cups of types I.1-I.4: approximately 0.4l. Most of the cups and goblets are slipped and burnished on both surfaces, which would have made them suitable for holding liquids, and cups could be used as drinking vessels too. Cups were very often grouped inside the graves together with small bowls (described below), and positioned near animal bones deposited as food offerings [Fig. 4.1, T.2 Chamber 3]. Dates and animal bones were discovered inside the goblets found at Ballana and Qustul (Emery and Kirwan 1938, 394). Cups also served a second function as lids for large handmade jars [Fig. 4.1]. During the excavations, such vessels were found in situ, placed upside down over the mouth of a jar, or sometimes the right way up with the base of the cup blocking the mouth of the jar. This 
practice has also been noted at another archaeological site, namely El-Hobagi, where vessels similar to El-Zuma bowls II.2-II.3 were used as lids (Lenoble 2018, 322). An alternative to using this type of lid was to stop a vessel with organic material. This method of closure can sometimes still be observed in Sudanese households (Mahmoud ElTayeb, personal communication).

Large bowls (Adams' Class T) corresponding to ElZuma types II.7, II.8 and II.9 (Adams 1986, 1 and 2:35, 159, Fig. 70:1, 6, 7;16o, Fig. 71:13). Only one large handmade bowl was found in situ in the burial chamber of T.11, and its capacity is approximately $40 \mathrm{ol}$. Some animal bones were found inside this bowl, suggesting that it may have been used as a food-serving vessel in the grave (Volume I, Chapter 8; Mahmoud El-Tayeb and Czyżewska 2011, 116-117).

Jugs (Adams' Class I) corresponding to El-Zuma type XIV.2 jugs (Adams 1986, 1 and 2:35, 141, Fig. 52:12), and table amphorae (Adams' Class J) corresponding to ElZuma types XII.4, XII.5 and XII.6 (Adams 1986, 1 and 2:35, 143 Fig. 54: 4, 5; 144 Fig. 55:10). Jug Z15/26 (XIV.2) has a capacity of 3.5 l. The smaller amphora $Z_{15} / 56$ (XII.4) has a capacity of $0.6 \mathrm{l}$, amphora $\mathrm{Z}_{15} / 5$ has capacity of $1.6 \mathrm{l}$, while the largest specimen of this type $\left(\mathrm{Z}_{2} / 3_{2}\right)$ could hold 3.ol. Small amphora Z25/6 (XII.5) has a capacity of about 1.ol, and the larger amphora $\mathrm{Z}_{4} / 2+\mathrm{Z}_{4} / 10.11$ (XII.6) has a capacity of 5.5 l.Jugs and table amphorae found in tumuli could have been used for serving liquids as a burial offering.

Jars (Adams' Class W) corresponding to El-Zuma jars of group VII (Adams 1986, 1 and 2:36, 168, Fig. 79:16; 170, Fig. 81:31), and transport amphorae for wine or oil (Adams' Class Z) corresponding to El-Zuma amphorae of types XII.1, XII.2 and XII.3 (Adams 1986, 1 and 2:36, 178, Fig. 89:6, 9; 180, Fig. 91:17) could have been used as storage vessels in grave contexts. Jars of type VII differ in shape and size, occurring in small, medium, and large varieties with a narrow or broad belly. All of these parameters have a huge impact on the capacity of the vessels. Small jars of up to $20 \mathrm{~cm}$ in height have a capacity of between $1.5 \mathrm{l}$ and $3.0 \mathrm{l}$, vessels with a height of $20-30 \mathrm{~cm}$ have a capacity of 3.0-8.ol, jars and bottles measuring $30-40 \mathrm{~cm}$ high have a capacity of 12.0-20.ol, and the larger ones that are over $40 \mathrm{~cm}$ high have a capacity ranging from $18.0 \mathrm{l}$ to as much as 34.ol. Some of the jars in the El-Zuma assemblage have slipped surfaces, suggesting that they could have been used for storing liquids, but there is also a large group of jars and bottles without any additional surface treatment that are more likely to have served as containers for solids.

Small jugs/juglets imported from Egypt and the Mediterranean area (Adams' Class $\mathrm{M}$ ) corresponding to ElZuma jugs of type XIV.1 (Adams 1986, 1 and 2:36, 147 Fig. 58: 9), and bottles (Adams' Class N) (Adams 1986, 1 and 2:36,
148 Fig. 59: 8, 10) corresponding to El-Zuma vessels of types XIII.1 and XIII.2 (Adams' Class G) (Adams 1986, 1 and 2:36, 137 Fig. 48: 32) could have contained ointments. Small bottle Z6/7 (XIII.1) has a capacity of 0.41 , and bottle Z23/31 has a capacity of $1.3 \mathrm{l}$. Vessels of this sort found at Ballana and Qustul were filled with a heavy, greasy substance which, according to Emery, may have been some kind of ointment (Emery and Kirwan 1938, 391).

The function of spouted bowls found at El-Zuma is uncertain. The assemblage includes large, handmade, spouted bowls which occur in open and closed forms. Their capacity is between 3.ol and 5.ol. Only one vessel, from four recorded, was found in the main burial chamber; the rest were found in shafts or tunnels and their original location is uncertain, which makes it difficult to draw any conclusions about the function of these bowls in the burial rite. They may have been used in beer production (see Chapter 3.6, this volume) or, as Mahmoud El-Tayeb suggests, they may have been employed in a purification ceremony that was part of a burial custom (Mahmoud El-Tayeb 2012, 101). We cannot rule out that these vessels could have been used either as containers for food and drink or as liturgical vessels that were used in a purification ritual.

Lamps (Adams' Class P) (Adams 1986, 1 and 2:36, $15^{2}$ Fig. 63: 14-15) corresponding to El-Zuma vessels of group $\mathrm{x}$. Lamps in the El-Zuma repertoire are likely to be connected with burial looting. Lamps were discovered inside the tunnels, close to the walls or, for example, at the top of the fill of tunnels (see Volume I, Chapter 3, Fig. 3.34).

Qawadis (Adams' Class V) (Adams 1986, 1 and 2:36, 165 Fig. 76) corresponding to El-Zuma vessels of group XI. These jars were used in conjunction with a saqiya. The saqiya was invented in Egypt somewhere between the 2nd and 1st centuries BC. A painting in the tomb at Waradin depicts a saqiya turned by two oxen goaded on by a young boy (Venit 1989). The saqiya waterwheel was probably introduced into Ancient Nubia from Egypt in the very Late Meroitic period, first appearing in the Dodekaschoinos in Romano-Egyptian contexts. In the 4 th and $5^{\text {th }}$ centuries AD, large numbers of qadus jars from saqiya wheels occurred in post-Meroitic contexts in Lower and Upper Nubia (Edwards, n.d., 153, 203-204, see also Volume I, Chapter 1.2). In the El-Zuma repertoire, qawadis are probably linked to the activity of grave robbers or maybe grave builders, but they did not serve as funerary goods. Most sherds of this type in the El-Zuma repertoire were used as scrapers and were found in the tumulus superstructures or the fill of shafts and tunnels (see below, Chapter 4.3). 

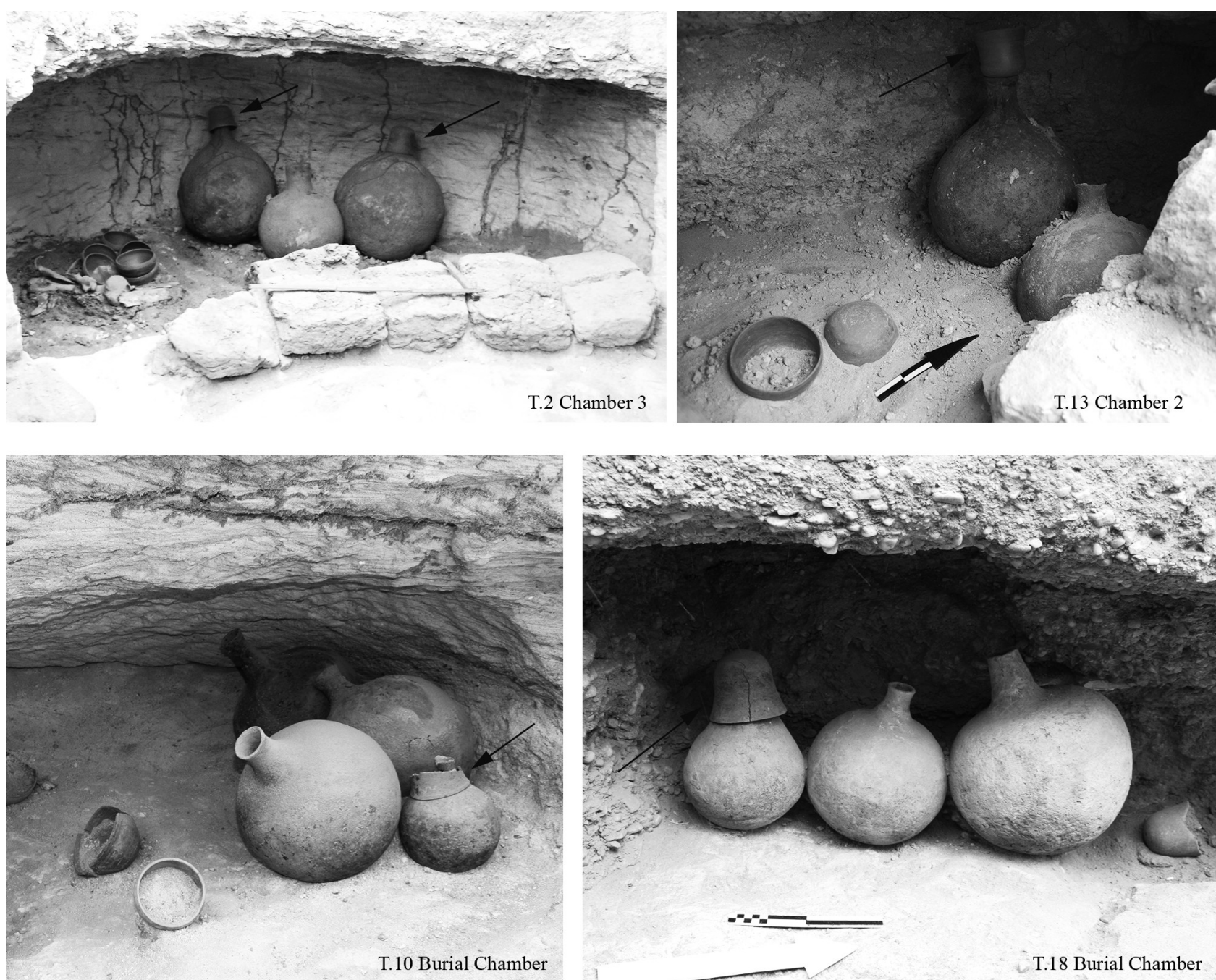

FIGURE 4.1 Cups used as lids for jars and bottles

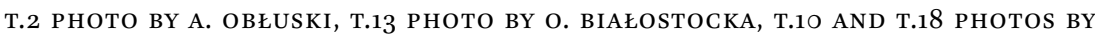

K. KOTLEWSKI

\section{Evidence of Vessel Use}

Pottery analysis and observation of the vessel surfaces prompted the following question: Were the ceramic grave goods new, and made especially for the burial ritual, or had they been in use before their deposition? Some vessels look like they were placed in the grave brand new, but in many instances traces of use are visible on the pottery surface. Scratches, scrape marks, and surface sheen from wear can be seen inside the vessels, especially at the bottom. Changes in surface colour inside the vessels and traces of soot on the external surface could also be indicative of vessel use. Sometimes it is difficult to say whether or not vessels had been used because both surfaces are damaged as a result of their deposition in the grave.

In the case of small vessels for serving food and drink and cooking vessels it is possible that some of them were placed in the grave as new, but others were used items.
Traces of use are clearly visible on jars and large bowls in the form of scratch marks/decoration and repairs to these vessels. Scratched decoration appears mainly on large jars and was executed on the neck and shoulder. This type of decoration may have been added to the vessel by its owner (Czyżewska-Zalewska 2016, 738). Scratched motifs also occur on a small bowl of type II.3 in the El-Zuma assemblage (see Chapter 7 , Cat. 119, this volume). A similar example of incised decoration on the shoulder and neck of jars was recorded at Abu Rtela (Malykh 2017). Patterns like those on the pottery were depicted in rock art and on the walls of temples in Musawwarat es-Sufra, and can be interpreted as an owner's mark, but may also have had a protective or magical meaning (Kleinitz 2009). We cannot say at the moment whether these signs and/or protective symbols were executed especially for the deceased, who was the owner of the grave, or whether they were connected with the buried individual or their family, who used 
the vessel for some time before its deposition in the grave. From a religious perspective, such decoration could easily be interpreted as magical and protective symbols.

Repairs to a vessel, as described in an earlier article (Czyżewska-Zalewska 2016, 376-379), show that it was used for a considerable span of time before being deposited in the burial. In the El-Zuma assemblage, traces of vessel repairs have been observed in large bowls and jars. The handmade bowl discovered in the burial chamber of T.11 (see Chapter 7, Cat. 167, this volume) has a number of small holes perforated on both sides of a long crack extending from top to bottom (Mahmoud El-Tayeb and Czyżewska 2011, 116-117). The walls were joined, probably using some kind of organic material like string, but no trace of any organic substance survives in any of the perforations. Small holes perforated in the broken neck of some jars also provide evidence of repairs (see Chapter 7, Cat. 246, 290, 291, this volume). In such cases, the neck and rim were probably restored with organic materials, but no trace of them survived in ElZuma. A jar that had had its neck restored using organic material was recorded at site 45 in El-Kassinger Bahry. The neck had been lost in antiquity and replaced with leather, which in turn disintegrated when the grave was opened (Mahmoud El-Tayeb 1998, 37). This repair technique was known prior to the Early Makurian period. Vessels with holes were discovered, for example, in CGroup contexts in Lower Nubia and dated to 25001200 BC (Williams 1993, 68). Repaired vessels were also deposited in graves at the El-Hobagi cemetery (Lenoble 2018, 40,6o-63). This technique is still used today in Sudan, where large vessels are mended by drilling holes in their broken walls and lashing them together with a string or wire (Czyżewska-Zalewska and Kowarska, forthcoming).

\section{Reused Pottery}

Another important aspect of the pottery is the 'second life' of vessels and sherds. In the El-Zuma assemblage this category is not connected with the deceased and burial customs, but with the looting or possibly building of tumuli.

\subsection{Scrapers/Digging Tools}

Large bowls (types II.7, II.8 and II.9); qawadis (group XI); storage jars (group VII). Sherds of these vessels were used as digging tools/scrapers [Fig. 4.2]. Such scrapers were discovered mainly in the shaft fill, tunnels or superstructure fills. The practice of using sherds as digging tools or scrapers was known in antiquity. They were used either by grave robbers or by grave constructors to excavate the original structure, for example during the Kerma period (Old Kush) at Hosh el-Guruf (Emberling and Williams 2010, 25).

\subsection{Lampshade}

Reuse of an imported amphora (of type XII.2) as a lamp, or more precisely as a lampshade (see Chapter 7 , Cat. 319, this volume). This vessel was found in two pieces. Several large holes $(1-2 \mathrm{~cm}$ in diameter) had been made at the top of the vessel, while the internal surface was smoked, suggesting that looters might have used amphorae as lampshades to protect the flame when plundering a grave. The bottom part of the vessel is broken off (the join spot is too small to reconstruct the vessel), but the interior of the base is clean without any traces of smoke. The broken toe of the vessel was used as a plug for the amphora. No parallel for the reuse of an amphora as a lampshade has been attested. It should be noted that four oil lamps were also found in the tunnel of T.4. 

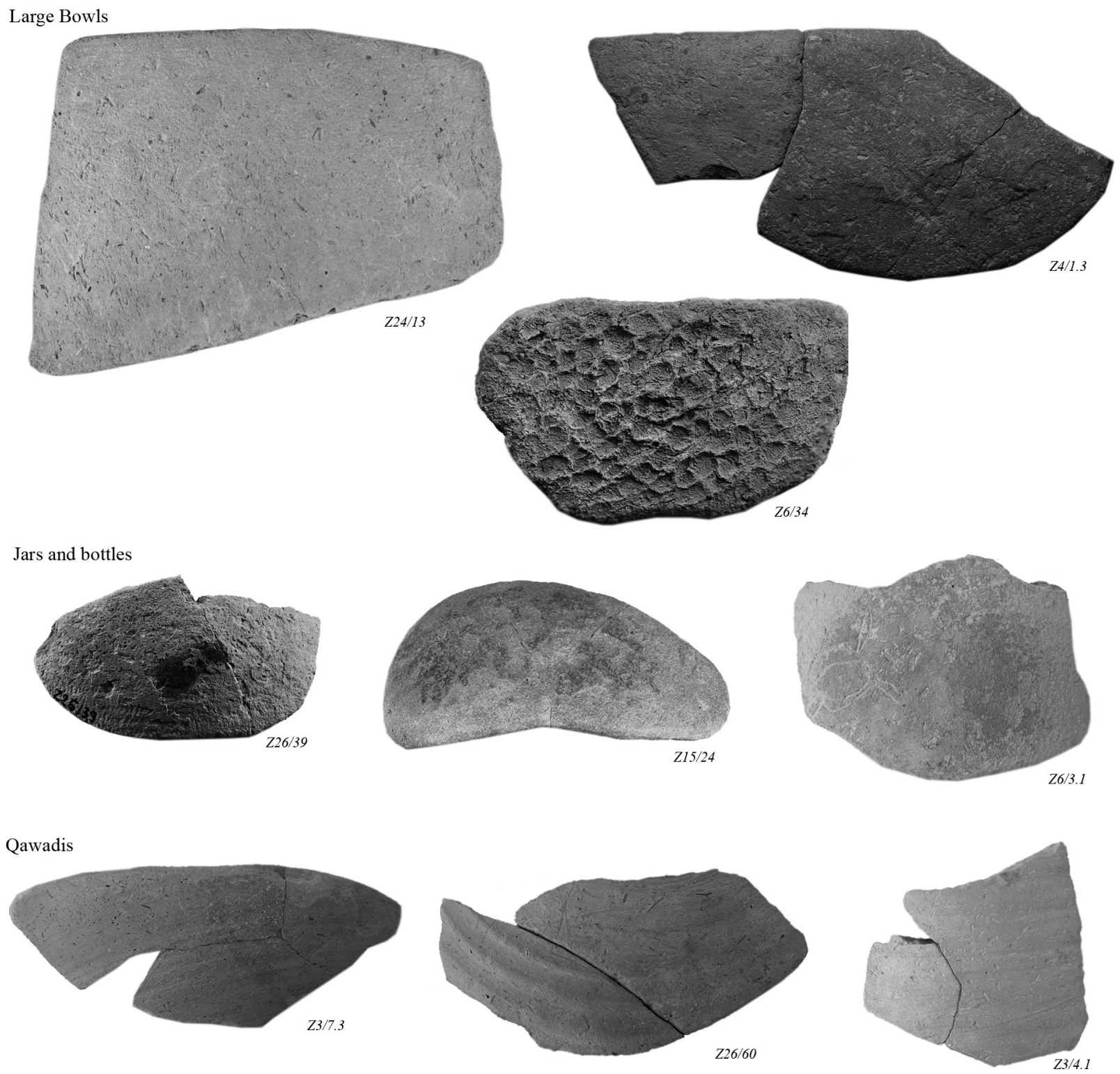

FIGURE 4.2 Scrapers/digging tools made from different types of vessels PHOTOS BY A. KAMROWSKI 